\title{
Short-Term Memory, Verbal Competence, and Age as Predictors of Imagery Instructional Effectiveness
}

\author{
Michael Pressley, Teresa Carigila-Bull, and Shelley Deane \\ Siniverity of Wastern Ontaries
}

$A N I)$

WOLfGank; SCHNEIDER

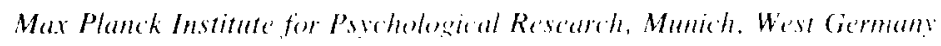

\begin{abstract}
Children 6 to 11 years of age heard concrete sentences that they were anked to learn. Half the subjects were instructed to construct images representing the sentence meanings. The remaining participants were provided no strategy instructions (control condition). Consistent with previous outcomes, the older children in the imagery condition learned signficantly more than did the older control subjects. There was a slight trend favoring imagery for younger children in the sample. Individual differences in short-term memory and verbal competence were more highly associated with performance in the imagery than in the control condition. such that greater shorterm memory and werhal competence predicted better sentence learning in the imagery condition. In particular, hort-term nemory and verbal competence made unigue contributions (relative to age and to sach other) to prediction of sentence learning in the imagery condition, hut not in the control condition. In short. imagery instruction is more effective with children who are more intellectually competent. a los scidemic Prow. Im
\end{abstract}

Many studies of children's imagery were conducted in the last decade, stimulated in part by theories of imaginal representation (e.g., Kosslyn. 1980; Paivio, 1971; Piaget \& Inhelder. 1971). Additional pragmátic motivation for this research was provided by the hypothesis that improvements in learning, memory. and comprehension would follow from imaginal encoding (e.g., Levin, 1976; Pressley, 1977). The assumption in at number

This research was supported by a grant to the first author from the Nalural Sciencen and Engineering Reserch Council of Canatia. Reprint requests should be directed to Michael Pressley at the Department of Psychology, University of Western Ontario. London. Ontario N6A SC2. Canada. 
of experiments was that children suffer from a production deficiency (Flavell, 1970) with respect to imagery. That is, children have the competence to produce imaginal mediators but often fail to do so when imagery would aid learning. An hypothesis that followed from this perspective was that children's learning would be improved if they were instructed to generate imaginal representations.

As in a number of previous instructional investigations of children's imagery, the main dependent variable of interest in the experiment reported here was memory for concrete sentences. Six- to twelve-year-old subjects either acquired sentences following an imagery-generation direction, or were left to their own devices to learn the materials (control condition). This latter condition was comparable to the control group in other studies of imagery, with the assumption that children would not use imaginal mediation in this condition (e.g., Digdon, Levin, \& Pressley, 1985; Guttmann, Levin, \& Pressley, 1977: Levin, Bender, \& Pressley, 1979: Purkel \& Bornstein, 1980; Ruch \& Levin, 1979). Following the logic of the production deficiency hypothesis, learning would be expected to be better in the imagery-instructed condition, since participants in that cell would be induced to use an effective coding technique that would otherwise not be employed.

The production deficiency hypothesis has been supported inasmuch as there are many occasions when children's learning improves following instructions to produce images (Ghatala \& Levin, 1976: Levin, 1976: Pressley, 1976). Just as striking. however, are individual differences in susceptibility to imagery training-some children do not benefit from instructions to produce imaginal mediators. To date, the most frequently investigated individual differences variable in studies of children's imagery has been age. A common outcome in these research efforts was that a given imagery strategy would significantly improve performance at some particular age level, but fail to do so with younger children. This pattern is replicable across many learning situations (Pressley, 1977; Pressley \& Levin, 1977b, 1978), although the specific ages indexing the shift vary from paradigm to paradigm.

Of particular relevance here is that this developmental pattern holds when children are instructed to construct imaginal representations of concrete sentences that they hear. Generalizing across studies, 5- to 6year-olds who are told how to construct imaginal representations of sentences fail to learn more compared to same-age control subjects. The benefits of imagery training first occur between 6 and 7 years of age and increase gradually until the end of the grade-school years le.g., Digdon et al., 1985: Guttmann et al. 1977: Levin et al. 1979: Purkel \& Bornstein, 1980; Ruch \& Levin, 1979). The usual interpretation is that older children can generate images representing sentences, whereas younger children 
either cannot do so or do so much more variably than oider children (e.g., Levin, 1981; Levin \& Pressley, 1981).

A main purpose of the investigation reported here was to examine another individual differences variable that might be a potent predictor of whether children can benefit from an imagery strategy for learning prose, a variable less inclusive and more theoretically meaningful than age. Imagery-generation skill may be tied to how much information a learner can maintain in consciousness at any one time-that is, to functional short-term memory (Case, 1985, Chapter 13; Dempster. 1981). Functional short-term memory is a product of (a) storage capacity due to biological factors, (b) management of that biologically determined capacity by executive factors, and (c) the learner's knowledge base (e.g., Case, 1978; Chi, 1978). A main characteristic of short-term memory is that only a few storage and processing activities can be carried out at any one time. This limitation may be critical to imagery strategy use because creation of imaginal representations requires that the learner perform several activities simultaneously. For the specific case of creating images to represent concrete sentences, the learner must (a) hold the sentence in memory, (b) retrieve or construct images of each object and event represented in the sentence, and (c) combine the component images into at coherent representation of the sentence meaning. Some children may lack the functional short-term memory to carry out all of these operations at once. If so, individual differences in short-term memory should predict sentence learning when children are coding imaginally.

General verbal knowledge, as reflected by performance on the Peabody Picture Vocabulary Test-Revised, wats also studied here as a predictor of successful imagery use. Since improvements in execution of some verbal learning strategies are linked to changes in verbal competence (e.g.. Rabinowitz, 1984; Rohwer, Rabinowitz. \& Dronkers. 1982; Tarkin. Myers, \& Ornstein, manuscript in preparation), it seemed possible that a relationship with verbal knowledge might hold for imagery as wellgeneration of images representing the meanings of sentences depends in part on ready access to verbal concepts and the ways that concepts are interrelated. We were particularly interested, however, in determining if short-term memory would be a significant predictor of performance (particularly in the imagery condition), even with verbal ability accounted for. Such incremental validity would provide great motivation for additional study of short-term memory factors as predictors of strategy utility.

\section{METHODS}

\section{Subjects}

One hundred thirty-four children (65 males and 68 females) served as participants in the study. These included 22 grade 1,20 grade 2, 30 grade 
3, 28 grade 4, 23 grade 5, and 11 grade 6 children. The subjects attended a public school drawing from a middle- to upper-middle-class neighborhood of a medium-sized North American city. The children were randomly assigned to the imagery and control conditions, except that (a) approximately equal numbers of girls and boys were assigned to the imagery and control conditions, and (b) approxiately half of the children at each age level were assigned to the control condition and half to the imagery condition.

\section{Measures and Procedures}

The child first performed three short-term memory tasks, in counterbalanced order. These were followed by the sentence-learning task that was the dependent variable of interest here. The short-term memory tasks were administered before the sentence learning task so that subjects in the instructed condition would not have been exposed to information about the imagery strategy that could have conceivably had some effect on their performance on the short-term memory measures. Administration of the Peabody concluded the session. All of this testing required 45 to 65 min per child.

Sentence-learning task (dependent variable). Each subject was presented two 10-sentence lists, with the order of presentation of lists counterbalanced. List A consisted of 10 subject-verb-object sentences, with the subject modified by a descriptive adjective and the object specified by color. List B consisted of subject-verb-object sentences, with the object modified by an adjective and either the location of the action or the weather conditions at the time of the action specificd in either an introductory subordinate clause or in a modifying clause at the end of the sentence. These List A and B sentences, which are presented in the Appendix, were like the ones used in Levin et al. (1979) in that a subject-verb object was the core relationship that was accompanied by two pieces of less central content. The sentences were presented in a male voice on audio tape, with one sentence presented every $10 \mathrm{~s}$. Two lists of 10 sentences were used, with the types of sentences varying in the two sets, because it proved impossible to construct a list of 20 sentences with nonoverlapping modifying phrases and adjectives. (There are only so many colors, locations, and weather conditions!!) Most importantly, all sentences contained highly concrete meanings. Also, with 10 sentences per set, it was possible to avoid ceiling and floor effects for all subjectspilot testing suggested that there would be floor effects with the younger children if one 20-sentence list had been employed.

After presentation of each 10-sentence list, subjects were provided a series of probe questions for each sentence on the list. These questions required recall of four pieces of information from the sentence. For List A. subjects had to recall the two adjectives, the verb, and the object of 
the sentence. For instance. for the sentence, "The skinny cat sang into the blue telephone," subjects were asked (1) "What did the cat look like?" followed by (2) "What did the skinny cat do?" followed by (3) "What did the skinny cat sing into?" with (4) "What color was the telephone that the skinny cat sang into?" ending the inquiry. If a subject recalled a piece of information before the question tapping that piece of information was posed, the relevant question was simply deleted. Thus, if a subject responded to the third "cat" question with the answer "blue telephone." the experimenter simply gave the subject credit for knowing the answer to question 4 without asking the question. For List B subjects had to recall the verb, the object, the adjective modifying the object. and either the place or the weather specified in the sentence. The four questions for the sentence, "While he was in the desert, the cowboy cleaned his coffee pot," were (1) "What did the cowboy do?", (2) "What did the cowboy clean?", (3) "What type of pot did the cowboy clean?". and (4) "Where was the cowboy when he cleaned his pot?" For both List $A$ and List B. a quarter point was scored for each of the pieces of information recalled from a sentence, so that the maximum longer term sentence memory score was 20.

The only time in the study that the imagery and control subjects were treated differently was during the administration of this sentence-learning task. Subjects in the imagery condition were informed that they would hear a series of sentences, and that their job was to remember the content of each one. They were told that an easy way to do this was to make up a picture in their head for each sentence. The subject was then provided a practice sentence and was asked to generate an internal image representing the content of the sentence. The participant was required to tell the experimenter what the internal image looked like, with this explanation followed by the experimenter showing the subject a picture incorporating all of the details of the sentence and explaining that an internal version of the picture would have been a good mental image. The subject's "memory" of the sample sentence was also probed using four questions, so that the nature of the test would be clear. Before presentation of each of the two 10-sentence lists, subjects were told that they could forget the sample items and they were reminded to make an image for each sentence that they heard.

Subjects in the control condition were informed that the easy way to remember the sentence was "to try really hard." They were also provided the practice sentence and the practice test questions. but they were not shown a pictorial representation for the practice item. The procedures otherwise were comparable to those used in the imagery condition.

Individual differences measures. Threc short-1erm memory measures were collected. One was short-term memory for word lists. a task similar to ones used in other studies of the development of short-term memory 
(Daneman \& Blennerhassett, 1984: Dempster, 1981, 1985). The second was an abridged version of a nonverbal short-term storage measure developed by Case and his associates. The third required immediate recall of sets of short sentences and was modeled after a test developed by Daneman and Blennerhassett (1984).

The short-term memory for word lists assessment involved a malevoiced, audiotaped presentation of increasingly longer sets of one-syllable common nouns (e.g., ground, fin, barn, can, pet, ear). Subjects were told that they could recall list items in any order, that recall per se was what was important. All words were presented at a one word per second rate. The participants first heard a 3-word list and attempted to recall it. A second 3-word list followed, with subsequent presentation of two 6-word, two 9-word, and two 12-word lists. The short-term word list score was the total number of items recalled correctly from all eight lists (maximum $=60)$.

The $M r$. Cucumber measure was an abridged version of the test developed by Case (1985). Each trial of the task began with a 2-s presentation of Mr. Cucumber, who had two eyes, two ears, a nose, two dimples, two arms, a mouth, and two legs. Trials differed as to the number (i.e., 1 to 6) and location (i.e.. eyes, ears, nose) of stickers that were placed on Mr. Cucumber. The child had been instructed to look carefully at the picture in order to remember where the spots were located. After the 2-s presentation of the item, the child stared at a line grid for $5 \mathrm{~s}$. Subjects were then presented a picture of $\mathrm{Mr}$. Cucumber without stickers with the requirements of pointing out the location of the spots. This sequence was repeated for 12 trials, with one-spot, two-spot, three-spot, four-spot, five-spot, and six-spot items (two of each item type), so that the total number of spots that could be recalled was 42 .

The short-term memory for sentenc's test consisted of the presentation and attempted recall of increasingly longer sets of audiotaped sentences, each sentence between three and seven words long. The sentences were taken from primary readers not used in the participating school district. The sentences in a set were read with approximately a half-second pause between sentences. The child was signalled to recall immediately after the last sentence in the set was concluded. The first list consisted of only one sentence. This was followed by six additional sets, each containing one more sentence than the previous one to a maximum of seven sentences. The score for this measure consisted of the number of words correctly recalled across all seven sets (maximum score $=144$ ).

We were aware from the outset that the short-term sentence measure was more similar to the sentence-learning task that was the dependent variable than were the other two short-term memory assessments. This short-term sentence measure was included, however, because of the 
prominence of this type of short-term memory assessment in the contemporary literature (e.g.. Daneman, 1982; Daneman \& Blennerhassett, 1984). Because of the emerging visibility of this type of measure, we especially wanted to generate short-term sentence memory data that could be compared with other short-term memory data, so that informed decisions could be made when selecting short-term memory measures in our future research on prose learning strategies. We were confident that the shared materials variance could be taken into account in analyzing and interpreting the data, and, in fact, that is done in the present Results and Discussion sections.

Dunn and Dunn's (1981) revised version of the Peabody Picture Vocabulary Test (Form L) served as a general verbal ability predictor variable in this study.

\section{RESULTS}

\section{Mean Levels of Performance as a Function of Experimental Condition and Sex}

The mean levels for the individual differences variables (short-term memory and Peabody raw scores) and the dependent variable (sentence learning) are reported in Table 1 as a function of sex and experimental condition. Each of these variables was analyzed with a 2 (sex) $\times 2$ (condition) analysis of variance (Kirk, 1982). There was only one significant main effect in these analyses: As expected, performance on the dependent variable was better in the imagery condition than in the control condition. $F(1.130)=8.64 . p<.004$. For the next highest main effect. $F(1.130)$ $=2.90, p>.09$. There was only one significant sex $\times$ condition interaction. It occurred in the Mr. Cucumber test data, $F(1,130)=4.49, p<.04$. Because this interaction was small, and not important in any way to any subsequent analyses or interpretations, it was not considered further.

Some of the correlational and regression analyses reported subsequently are based on an aggregation of short-term memory for word lists, shortterm memory for sentence lists. and $\mathrm{Mr}$. Cucumber. The aggregation was accomplished by summing over within-condition standardized scores ( $z$ scores) of the three short-term memory component scores. The mean for the short-term memory aggregation was 0 in both conditions, since this variable was the sum of three complete sets of $z$ scores. The SD = 2.36 in the imagery condition: $\mathrm{SD}=2.37$ in the control condition. Such an aggregation has several advantages over the component scores. An aggregated measure generally has greater reliability than its components (Rushton, Brainerd, \& Pressley, 1983). In addition, the aggregation better reflected the multiple facets of short-term memory (c.g.. Dempster. 1981. 1985) than did any of the component measures. 
TABLE 1

Mfan Levels and Standard Deviations of Predictor Variables and Predicted Sentence Learning as a Function of Experimentai. Condition

\begin{tabular}{|c|c|c|c|c|}
\hline \multirow[b]{3}{*}{ Variable } & \multicolumn{3}{|c|}{ Condition } & \\
\hline & \multicolumn{2}{|c|}{$\begin{array}{cc}\cdots \\
& \text { Imagery }\end{array}$} & \multicolumn{2}{|c|}{ Control } \\
\hline & Meán & $\mathrm{SD}$ & Mean & $\mathrm{SD}$ \\
\hline \multicolumn{5}{|c|}{ Predictor variables } \\
\hline \multicolumn{5}{|l|}{$\mathrm{Age}^{\prime \prime}$} \\
\hline Males & 105.84 & 19.05 & 106.32 & 18.68 \\
\hline Females & 104.00 & 19.17 & 105.49 & 19.57 \\
\hline \multicolumn{5}{|c|}{ Short-term word list ${ }^{h}$} \\
\hline Males & 27.53 & 4.29 & 28.44 & 5.33 \\
\hline Feruales & 27.91 & 5.20 & 27.91 & 4.50 \\
\hline \multicolumn{5}{|c|}{ Short-term sentence list } \\
\hline Males & 73.63 & 11.47 & 76.71 & 15.29 \\
\hline Females & 72.06 & 16.92 & 75.88 & 12.74 \\
\hline \multicolumn{5}{|c|}{ Mr. Cucumber" } \\
\hline Males & 27.19 & 5.47 & 25.91 & 4.90 \\
\hline Females & 24.14 & 3.15 & 26.24 & 4.68 \\
\hline \multicolumn{5}{|c|}{ Peabody raw scores } \\
\hline Males & 104.53 & 16.46 & 109.09 & 14.71 \\
\hline Females & 104.66 & 15.79 & 104.33 & 17.08 \\
\hline \multicolumn{5}{|c|}{ Predicted performance } \\
\hline \multicolumn{5}{|c|}{ Sentence Learning ${ }^{\prime}$} \\
\hline Males & 12.77 & 4.09 & 11.46 & 3.53 \\
\hline Females & 12.33 & 4.00 & 9.77 & 3.72 \\
\hline
\end{tabular}

Note. $N=32$ and 34 males in the imagery and control conditions. respectively: 35 and 33 females in the imagery and control conditions. respectively.

"In months.

${ }^{h}$ Number of words recalled, summed across lists; maximum $=60$.

Number of words recalled from sentences, summed across lists: maximum $=144$.

Number of spots correctly recalled, summed across items; maximum $=42$.

Raw scores; maximum $=175$.

' Number of sentences recalled, summed across lists: maximum $=20$.

\section{Effect of Imagery Instruction on Sentence Learning with Younger and Older Children}

The simple effect for imagery was significant among fourth, fifth, and sixth graders, with mean $=14.77$ for imagery and mean $=11.70$ for control subjects, $t(59)=3.64, p<.01\left(M S_{\mathrm{e}}=11.07\right)$. For the younger subjects, there was a nonsignificant trend favoring the imagery mean $(10.62)$ over the control mean $(9.69), t(70)=1.07, p>.20\left(M S_{c}=\right.$ 13.53). In summary, this pattern of results exactly replicates the pattern obtained in previous research, particularly in Levin et al. (1979). 


\section{Correlational Analyses}

The intercorrelations (Kirk, 1982) between the short-term memory and Peabody measures are displayed in Table 2 as a function of experimental condition. There are five important patterns that can be discerned from the correlational data. (a) There was a correlation with age (in months) for each of these variables, such that performance improved with increasing age. (b) Consistent with the position that the short-term memory measures were tapping a common construct, there were positive, significant intercorrelations between the three short-term measures in both the imagery and control conditions. (c) That none of the intercorrelations between short-term measures approached 1.00. however, suggests that short-term memory is far from unified. (d) There were large part-whole correlations. that is, between each of the short-term memory components and the short-term aggregation. (e) Performance on each of the short-term memory tasks was positively associated with Peabody scores.

Correlations involving the dependent variable were also conducted. Not surprisingly, sentence learning was positively correlated with age in both the imagery $(r=.59, p<.001)$ and control $(r=.40, p<.001)$ conditions. These correlations did not differ significantly, $Z=1.41, p$ $>.05$. The zero-order short-term memory and Peabody correlations with sentence learning are presented in Table 3 (left column). Consistent with the perspective that short-term memory is more important in the imagery than in the control condition. all three short-term memory measures and the aggregation were associated with predicted sentence learning in the imagery condition, but only the short-term memory of sentences and the aggregation were significantly associated with sentence learning in the control condition. The short-term memory for word lists and short-term memory aggregate correlations with sentence learning were significantly higher in the imagery than in the control condition, $Z=3.76$ and $Z=$ 2.62, respectively, both $p<.01$. Although the trends were in the direction of larger correlations in the imagery than in the control condition, the short-term memory for sentences and $\mathrm{Mr}$. Cucumber correlations with predicted sentence learning did not differ significantly between the two conditions, $Z=0.61$ and $Z=1.04$, respectively, both $p>.15$. Peabody scores were significantly associated with predicted sentence learning in both conditions, with the correlation significantly larger in the imagery than in the control condition, $Z=2.49, p<.02$.

A main concern was determining whether short-term memory and verbal competence are associated with sentence learning independent of the effects of age. Hence, Table 3 also contains partial correlations with age statistically controlled. Again, consistent with the perspective that short-term memory factors were more important in the imagery condition, three of the four correlations involving short-term memory indices were 


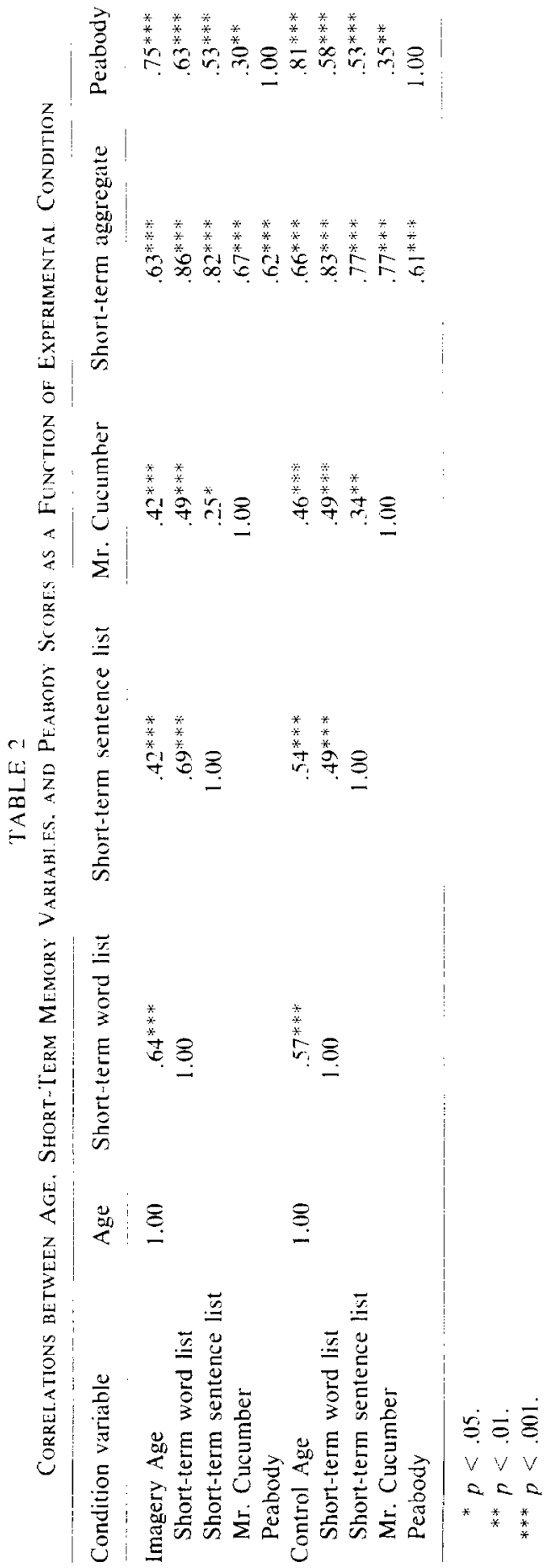


TABLE 3

Correlations and Partial Correlations (Age Controlifed) betwfern the Short-Term Memory and Peabody Predictor Measures and Predictfo Sentence learning as a Finction of Experimfintai. Condition

$$
\text { Zero-order correlations }
$$

Predictor

Short-term word list

Short-term sentence list

Mr. Cucumber

Short-term aggregate

Peabody

$$
\begin{aligned}
& * * p<.01 \text {. } \\
& \text { *** } p<.0001 \text {. }
\end{aligned}
$$

$\begin{array}{llll}\text { Imagery } & \text { Control } & \text { Inagery } & \text { Control } \\ .70^{* * *} & .20 & .51^{* *} & .18 \\ .63^{* * *} & .56^{* *} & .52^{* * *} & .45^{* * 4} \\ .35^{* *} & .18 & .14 & .01 \\ .71^{* * *} & .41^{* * *} & .54^{* * *} & .19 \\ .71^{* * *} & .42^{* * *} & 51^{* * *} & .18\end{array}$

Partial correlations

significant in the imagery condition. whereas only one of the short-term measures was significant in the control condition. As in the analyses of the zero-order correlations, all of the correlations involving short-term memory were higher in the imagery than in the control condition. The difference in magnitude between conditions was significant for the shortterm memory of word lists, $Z=3.38, p<.01$, and for the short-term memory aggregation, $Z=2.31, p<.05$. but not for the short-term memory of sentence lists or for the $\mathrm{Mr}$. Cucumber measure, larger $Z=$ $0.85, p>.15$. As was the case for the zero-order correlations, the partial correlation between Peabody performance and sentence learning was also significantly greater in the imagery than in the control condition. $Z$ $=2.13, p<.05$. The association between Peabody performance and sentence learning was significant in the imagery. but not in the control condition.

\section{Regression and LISREL Analyse's}

The relationships of short-term memory and Peabody scores to sentence learning were explored additionally in a series of regression (Draper \& Smith, 1981) and LISREL (LISREL IV; Jöreskog \& Sörbom. 1984) analyses. For reasons of economy, and because of the psychometric advantages of composites, we detail here only results from analyses in which short-term memory was calculated using all three short-term memory components. The short-term memory aggregation was used in the regression analyses. A "latent" variable was constructed for the LISREL analyses from the three short-term memory composite measures. Only regression and LISREL results that are informative over and above the outcomes reported thus far are presented.

The most telling regression analyses were those in which age was entered as a first predictor. Age was a significant predictor when entered 
first in both the imagery $\left(R^{2}=.35, F\right.$ to enter $\left.=34.79, p<.001\right)$ and the control $\left(R^{2}=.16, F\right.$ to enter $\left.=12.53, p<.001\right)$ conditions. In the imagery condition, the addition of both the short-term memory aggregation and Peabody to the regression equation additionally improved prediction of sentence learning (total $R^{2}$ with age, short-term aggregation, and Peabody in the equation $=.623$ ). This held both when short-term memory or Peabody was entered alone following age and when the two variables were entered one after the other following age. The smallest $F$ to enter $=12.01, p<.001$. That is, in the imagery condition, both short-term memory and Peabody scores contributed unique predictive variance relative to age and relative to each other. In contrast, in the control condition, once age was in the regression, neither short-term memory nor Peabody scores significantly incremented prediction (total $R^{2}$ with all three variables in the equation $=.209$ ), largest $F$ to enter $=2.51, p>.11$.

Additional regression analyses were conducted beyond those reported above. Space limitations do not permit detailed reporting of these results. It was notable, however, that in both conditions, age had little effect on prediction if entered into the regression equation after the short-term aggregate or Peabody measure (largest $R^{2}$ change in those cases $=.03$ ). These outcomes underscore the point that short-term memory and verbal ability are better predictors of children's performance than age per se (cf. Pressley \& Levin, 1977a; Rohwer et al., 1982).

LISREL (e.g., Pedhazur, 1983) analyses were conducted in order to assess the "causal" ordering of age, short-term memory, and verbal competence. Two alternative models were tested. In one of these models (Model A), age was specified as influencing verbal competence (Peabody) and short-term memory, with verbal competence having a significant (unidirectional) impact on short-term memory. Further, in Model A, verbal competence and short-term memory directly affected performance on the criterion measure (sentence learning). There was only one difference in the alternative model, Model B-short-term memory was specified as unidirectionally influencing verbal competence in $\mathrm{B}$.

Model A provided a better representation of the causal processes for both the imagery and the control conditions. In the imagery condition. the goodness of fit was poor for Model B, $\chi^{2}(7)=30.04, p<.001$, whereas a reasonably good fit was obtained for Model A, $\chi^{2}(7)=10.23$, $p>$.18. Similarly, the goodness-of-fit index for LISREL (which could vary between 0 and 1 , with higher values representing better fit) showed better fit for Model A (.95) than for model B (.62). The root mean square residual (a goodness-of-fit index for which values representing good fit approach 0) was .04 for Model A and .06 for Model B in the imagery condition. In the control condition, there was also a reasonably good fit for Model A, $\chi^{2}(4)=5.16, p<.27$. It proved absolutely impossible to fit the control data to Model $B$. The fit was so poor that an exact value 
of $\chi^{2}$ could not be determined, although it was clear that the value of this goodness-of-fit statistic deviated greatly from zero. In short. the LISREL analyses clarified the direction of the relationship between shortterm memory and verbal competence that was detected in all of the previous analyses. The relationship was due to verbal competence influencing functional short-term memory rather than the reverse.

The patterns of regression and LISREL outcomes reported here were also obtained when analyses were reconducted with the short-term sentences variable deleted (and thus, the materials overlap with the predicted measure eliminated). Given the large imagery versus control difference for the partial correlations involving short-term memory for words (reported previously), it is notable that the same pattern of regression outcomes was obtained with short-term memory represented by only the word list variable. The assumptions of LISREL, would have been badly violated with only one measure of short-term memory, and thus. no LISREL. analyses were conducted with short-term memory for words as a sole indicator.

\section{DISCUSSION}

The usual pattern in imagery research is for the imagery over control difference to be large enough to be significant at an older age level, with only a nonsignificant trend favoring imagery at a younger age level (e.g. Guttmann et al. 1977; Levin et al., 1980). That pattern was obtained in the sentence-learning data reported here.

Much more interesting than differences in outcomes as a function of age, however, were the relationships between sentence-learning performance and individual differences in functional short-term memory. In particular, children with higher short-term memory scores were more successful in the imagery condition than were children who were less able to hold a number of items in consciousness simultaneously, with the relationship between sentence learning and short-term memory much less pronounced in the control condition. The conclusion that functional short-term memory differences are a more important determinant of success in the imagery condition is also bolstered by the finding that short-term memory was a significant predictor in the imagery condition even with age and Peabody scores controlled statistically. In contrast, once age was considered in the control condition, there was no improvement in prediction of sentence learning due to consideration of the short-term memory aggregation. (In fact, only the short-term memory for sentence lists was predictive in the control condition with age controlled-a finding that could be accounted for by the materials overlap alone.) Consistent with other developmental data (Guttentag. 1984), it secms that when children are given control instructions to learn sentences. they rely on processes that do not put great pressure on short-term memory. 
The data obtained here linking short-term memory differences to successful imagery execution complement experimental demonstrations of improved imagery execution in young children when information processing demands are lowered. For instance, 7- to 8-year-olds' successful execution of imagery strategies for associative learning is dependent on presentation of materials so that processing demands are low (e.g.. with part of the image provided in the form of external pictures). In contrast, older children can generate mnemonic elaborations even when external support for imagery generation is low, and thus, processing demands are high (e.g., Pressley \& Levin, 1977. 1978). Children can also carry out imagery strategies with prose if they are provided part of the image in the form of a picture before they can carry out the strategy given no picture prompts (Guttmann et al.. 1977; Ledger \& Ryan, 1985; Ryan, Ledger. \& Weed, in press). One finding obtained by Ryan et al. (in press) is especially relevant: When 5- to 6-year-old children executed a prose imagery strategy given a lot of external support for the strategy in the form of pictures, individual differences assessments of short-term memory failed to predict success with the strategy. That finding makes sense from the perspective developed here-Short-term memory individual differences are only likely to predict performance when short-term memory is taxed.

We do note a bias in the short-term memory measures that we employed, one that should have led to underestimation of short-term memory effects if it had any impact at all. Performance on many short-term memory measures (i.e., ones tapping what has been referred to as working memory) is almost certainly a product of both storage and processing factors (e.g., Baddeley \& Hitch, 1974; Daneman \& Carpenter, 1980). In contrast, the short-term tasks in this experiment involved storage more than transformation, with no obvious transformation of the material required for any of the three short-term memory components. Given that imaginal coding presumably involves both storage and transformation, it seems reasonable to hypothesize that measures requiring more transformation (i.e., measures of working memory) might be even more predictive of imagery execution skills than storage-loaded measures. Explicit contrasts of short-term storage and working memory measures as predictors of complex strategy use should be carried out.

We also note that the short-term memory for sentences measure seems problematic as a measure to predict prose performance. Although measures similar to the short-term sentence assessment used here are being used in the prose/reading comprehension literature (e.g.. Daneman \& Blennerhassett, 1984; Daneman \& Carpenter, 1980), the material overlaps between this short-term measure and prose criterion tasks are striking. Although no mention was made of it until this point, this overlap was reflected in correlated measurement errors between the short-term memory for sentence lists and the criterion measure during the LISREL analyses 
(with appropriate adjustments made!). Thus, based on our data and on face validity characteristics of the short-term memory for sentences task. we believe that interpretive caution is warranted in the use of this type of short-term memory measure as a predictor of prose processing. It should be noted that we draw this conclusion despite the fact that there is nothing incompatible between the data obtained in this study and the outcomes reported by Daneman and her associates. In particular, the control condition correlation between short-term sentence learning and predicted sentence learning was greater than the control condition correlation between short-term word list learning and predicted sentence learning. The ordering of these relationships mirrors the ordering of Daneman's own correlations between aspects of children's short-term memory and their uninstructed listening comprehension (Daneman \& Blennerhassett, 1984).

More optimistically, short-term learning of words (the most traditional measure of short-term memory used here) does not have the same face validity problem. There was strikingly greater predictability from this measure in the presumably short-term-memory-demanding imagery condition than in the less demanding control condition. Based on this outcome. it seems that traditional assessments of short-term memory should be given serious consideration for use in research on capacity determinants of strategy execution skill.

The Peabody measure was included in this study largely to determine whether the effects of short-term memory could be separated from those due to simple verbal competence (Daneman \& Green, 1986; Masson \& Miller, 1983). The contributions of these two variables were separable to some extent in the regression analyses of the imagery condition, but they could not be separated using regression in the control condition. The LISREL analyses, however, permitted the conclusion in both conditions that verbal competence affects short-term memory more than short-term memory affects verbal competence. Verbally facile children can presumably comprehend words and sentences with less effort than required by less competent children. Thus, verbally capable children expend less short-term capacity on these subprocesses and consequently. they have more of their short-term memory available for learning and strategy execution than do less verbally able children.

In closing, we emphasize that children's failures to use imagery cannot always be reduced to simple production deficiencies that are overcome by instructions to generate imaginal mediators. More competent children (as indexed by short-term memory and verbal competence measures) are more likely to benefit from imagery instructions than are less competent children. This is probably because more capable children are better able to carry out the processes required to generate images than are less capable learners. 


\section{APPENDIX \\ List $A$ and List $B$ Criterion Sentences}

\section{List A}

The angry bird shouted at the white dog.

The skinny cat sang into the blue telephone.

The tiny alligator moved fast on his red scooter.

The sleepy bear dropped his pink ice cream cone.

The toothless man slept on the orange couch.

The fat boy ran with the grey balloon.

The bored woman rode the wild brown horse.

The smiling monkey climbed on top of the purple umbrella.

The scary monster chased the yellow car.

The crying girl stared at the green dessert.

\section{List $B$}

The rain fell on the dinosaur when he bit into the pine tree.

It was snowing when the mailman peeked into the candy store.

The hockey player photographed his paper airplane when he was in the mountains.

The policeman painted the circus tent on a windy day.

It was a sunny day when the lion stood on the bowling ball.

The pirate dropped the gold key in the middle of the jungle.

The waitress buried the silver plate in the cornfield.

While he was in the desert, the cowboy cleaned his coffee pot.

The beaver attacked the cabbage patch doll that was floating in the ocean.

The turkey pecked at the coke can laying on the highway.

\section{REFERENCES}

Baddeley, A. D., \& Hitch, G. (1974). Working memory. In G. H. Bower (Ed.), The psychology of learning and motivation (Vol. 8, pp. 47-89). London: Academic Press.

Case, R. (1978). Intellectual development from birth to adulthood. A neo-Piagetian interpretation. In R. S. Siegler (Ed.), Children's thinking: What develops? (pp. 37-72). Hillsdale, NJ: Erlbaum.

Case, R. (1985). Intellectual development: Birth to adulthood. Orlando: Academic Press.

Chi, M. T. H. (1978). Knowledge structures and memory development. In R. S. Siegler (Ed.), Children's thinking: What develops? (pp. 73-96). Hillsdale, NJ: Erlbaum.

Cronbach, L. J. (1970). Essentials of psychological testing (3rd ed.). New York: Harper \& Row.

Daneman. M. (1982). The measurement of reading comprehension: How not to trade construct validity for predictive power. Intelligence, 6, 331-345.

Daneman, M.. \& Blennerhassett, A. (1984). How to assess the listening comprehension skills of prereaders. Journal of Educational Psychology. 76, 1372-1381.

Daneman, M., \& Carpenter. P. A. (1980). Individual differences in working memory and reading. Journal of Verbal Learning and Verbal Behavior, 19, 450-466.

Daneman, M.. \& Green. I. (1986). Individual differences in comprehending and producing words in context. Journal of Memory and Language, 25, 1-18. 
Dempster. F. N. (1981). Memory span: Sources of individual and developmental differences. Psychological Bulletin, 89, 63-100.

Dempster, F. N. (1985). Short-term memory development in childhood and adolescenct. In C. J. Brainerd \& M. Pressley (Eds.). Basic processes in memony development (pp. 209-248). New York: Springer-Verlag.

Digdon. N.. Pressley. M. \& Levin. J. R. (1985). Preschoolers learning when pictures do not tell the whole story. Educational Communication and Terhology Joumal, 33. $139-145$.

Draper, N., \& Smith. II. (1981). Applied regression andysis (2nd ed.). New York: Wiley

Dunn. L. M.. \& Dunn. L. M. (1981). Peabody picture botabulary test-Rerised. Circle Pines. MN: Amer. Guidance Serv.

Flavell. J. H. (1970). Developmental studies of mediated memory. In H. W. Reese \& 1.. P. Lipsit1 (Eds.). Adrances in child development and behavior (Vol. 5. pp. 182-2111. New York: Academic Press.

Ghatala, E. S.. \& Levin. J. R. (1976). Children's recognition memory processes. In J. R. Levin \& V. L. Allen (Eds.), Cosmitive l'arning in children: Theories and strategies (pp. 61-100). New York: Academic Press.

Guttentag. R. E. (1984). The mental effort requirement of cumulative rehearsal: A developmental study. Jentral of Experimental Child Psychology. 39, 546-561.

Guttmann. J.. I evin. J. R., \& Pressley. M. (1977). Pictures, partial pictures, and young children"s oral prose learning. Journal of Edwatiomal Psychology. 69, 473-480.

Jöreskog, K. S. \& Sörbom. D. (1984). LISREL N A Amlysis of linear simetural relationships

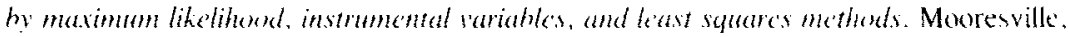
IN: Scientific Software.

Kirk. R. E. (1982). Experimental design: Procedures for the behavisul sidences (2nd ed.1. Belmont. CA: Brooks/Cok.

Kosslyn, S. M. (1980). Image and mind. Cambridge. MA: Harvard Univ. Press

Ledger, G. W. . \& Ryan. E. B. 1 1982). The effects of semantic integration training on recall for pictograph sentences. Journal of Exporimental Child Psychologs, 33, 39-54.

Levin, J. R. (1976). What have we learned about maximizing what chiddren learn? In J, R. Levin \& V. L. Allen (Fds.). Cognitive letrning in rhildren: Theories and strategies (pp. 105-134). New York: Academic Press.

Levin, J. R. (1981). On functions of pictures in prose. In F. J. Pirozzolo d M. C. Wittrock (Eds.). Neuropsychologiral and cognitive processes in reading (pp. 203-228). New York: Academic Press.

Levin, J. R. Bender, B. G., \& Pressley, M. (1979). Pictures, imagery, and children's recall of central versus peripheral sentence information. Edacational communication and Technology Journal, 27, 89-95.

Levin, J. K., \& Pressley, M. (I98I). Improving children s prose comprehension: Selected strategies that seem to succeed. In C. M. Santat \& B. L. Hayes (Fds.), Children's prose comprehension: Rescarch and practice (pp. 44-71). Newark. DE: Int. Reading Assoc.

Masson, M. E. J., \& Miller. J. A. (1983). Working memory and individual differencen in comprehension and memory of text. Journal of Educational Psychology. 75, 314-318.

Paivio. A. (197)). Imagery and verbal processes. New York: Holt. Rinehart. \& Winston.

Pedhazur. E. J. (1983). Multiple regression in behatioral research. New Yurk: Holt. Rinehart, \& Winston.

Piaget, J., \& Inhelder, B. (1971). Mental imagery in the child. New York: Basic Books.

Pressley, M. (1976). Mental imagery helps eight-year-olds remember what they read. Journal of Educational Psycholog! 68, 355-359.

Pressley, M. (1977). Imagery and children's learning: Putting the picture in developmental perspective. Review of Educational Research, 47, 585-622. 
Pressley, M.. \& Levin, J. R. (1977a). Developmental differences in subjects` associative learning strategies and performances: Assessing a hypothesis. Journal of Experimental Child Psychology, 24, 431-439.

Pressley, M., \& Levin. J. R. (1977b). Task parameters affecting the efficacy of a visual imagery learning strategy in younger and older children. Journal of Experimental Child Psychology, 24, 53-59.

Pressley, M., \& Levin, J. R. (1978). Developmental constraints associated with children's use of the keyword method of foreign language vocabulary learning. Journal of EXperimental Child Psychology, 26, 359-372.

Purkel. W.. \& Bornstein, M. H. (1980). Pictures and imagery both enhance children's short-term and long-term recall. Developmental Psychology, 16, 153-154.

Rabinowitz, M. (1984). The use of categorical organization: Not an all-or-none situation. Journal of Experimental Child Psychology, 38, 338-351.

Rohwer, W. D.. Jr.. Rabinowitz. M., \& Dronkers, N. F. (1982). Event knowledge, elaborative propensity, and the development of learning proficiency. Journal of Experimental Child Psychology, 33, 492-503.

Ruch, M. D., \& Levin, J. R. (1979). Partial pictures as imagery-retrieval cues in young children"s prose recall. Journal of Experimental Child Psychology, 28, 268-279.

Rushton. J. P.. Brainerd, C. J., \& Pressley. M. (1983). Behavioral development and construct validity: The principle of aggregation. Psychological Bulletin, 94, 18-38.

Ryan, E. B., Ledger, G. W., \& Weed, K. A. (in press). Acquisition and transfer of an integrative imagery strategy by young children. Child Development.

Tarkin, B., Myers, N. A., \& Ornstein, P. A. (in preparation). The effects of stimulus meaningfulness on children's spontaneous rehearsal strategies. Chapel Hill, NC: Department of Psychology, University of North Carolina at Chapel Hill.

RfCFived: June 13, 1986: Revised: December 1, 1986. 